\title{
Optimal Redesign of the Dutch Road Network
}

\section{Snelder, A.P.M. Wagelmans, J.M. Schrijver, H.J. van Zuylen and L.H. Immers}

\begin{tabular}{|l|l|}
\hline \multicolumn{2}{|l|}{ ERIM REPORT SERIES RESEARCH IN MANAGEMENT } \\
\hline ERIM Report Series reference number & ERS-2005-091-LIS \\
\hline Publication & December 2005 \\
\hline Number of pages & 22 \\
\hline Persistent paper URL & \\
\hline Email address corresponding author & wagelmans@few.eur.nl \\
\hline Address & Erasmus Research Institute of Management (ERIM) \\
& RSM Erasmus University / Erasmus School of Economics \\
& Erasmus Universiteit Rotterdam \\
& P.O.Box 1738 \\
& 3000 DR Rotterdam, The Netherlands \\
& Phone: $\quad+31104081182$ \\
& Fax: $\quad+31104089640$ \\
& Email: info@erim.eur.nl \\
& Internet: $\quad$ www.erim.eur.nl \\
\hline
\end{tabular}

Bibliographic data and classifications of all the ERIM reports are also available on the ERIM website: www.erim.eur.nl 


\section{ERASMUS RESEARCH INSTITUTE OF MANAGEMENT}

\section{REPORT SERIES}

\section{RESEARCH IN MANAGEMENT}

\begin{tabular}{|c|c|}
\hline \multicolumn{2}{|c|}{ ABSTRACT AND KEYWORDS } \\
\hline Abstract & $\begin{array}{l}\text { The Dutch national road network has been developed over several decades. In the past, roads } \\
\text { were constructed according to the then current spatial and transportation planning philosophies. } \\
\text { Because the existing road network is a result of a long process of successive developments, the } \\
\text { question can be asked whether this network is the most appropriate from the current point of } \\
\text { view, especially taking in consideration the current socio economic structure of the Netherlands. } \\
\text { To answer this question an optimization algorithm for designing road networks has been } \\
\text { developed. With this algorithm the Dutch road network has been redesigned based on } \\
\text { minimization of the travel and infrastructure costs and by taking into account the socio economic } \\
\text { structure of the Netherlands. A comparison between the existing network and the new design } \\
\text { shows that the redesigned Dutch national road network has significantly lower total costs than } \\
\text { the existing road network. It is found that the construction of less roads with more lanes on } \\
\text { different locations leads to a reduction of the total travel time and the total vehicles kilometers } \\
\text { traveled. }\end{array}$ \\
\hline Free Keywords & Network Design Problem, Road Network, Netherlands, Redesign, Scratch, Motorway \\
\hline Availability & $\begin{array}{l}\text { The ERIM Report Series is distributed through the following platforms: } \\
\text { Academic Repository at Erasmus University (DEAR), DEAR ERIM Series Portal } \\
\text { Social Science Research Network (SSRN), SSRN ERIM Series Webpage } \\
\text { Research Papers in Economics (REPEC), REPEC ERIM Series Webpage }\end{array}$ \\
\hline Classifications & $\begin{array}{l}\text { The electronic versions of the papers in the ERIM report Series contain bibliographic metadata } \\
\text { by the following classification systems: } \\
\text { Library of Congress Classification, (LCC) LCC Webpage } \\
\text { Journal of Economic Literature, (JEL), JEL Webpage } \\
\text { ACM Computing Classification System CCS Webpage } \\
\text { Inspec Classification scheme (ICS), ICS Webpage }\end{array}$ \\
\hline
\end{tabular}




\title{
Optimal Redesign of the Dutch Road Network
}

\author{
M. Snelder ${ }^{\text {a,b,*}, \text { A.P.M. Wagelmans }}{ }^{c}$, J.M. Schrijver ${ }^{a}$, H.J. van Zuylen ${ }^{b}$, L.H. Immers ${ }^{\text {a,d }}$ \\ ${ }^{\mathrm{a}}$ TNO, Van Mourik Broekmanweg 6, P.O. Box 49, 2600 AA Delft, The Netherlands \\ ${ }^{b}$ Delft University of Technology, Faculty of Civil Engineering and Geosciences, Department of \\ Transport and Planning P.O. Box 5048, 2600 GA Delft, The Netherlands \\ ${ }^{c}$ Econometric Institute, Erasmus University Rotterdam, P.O. Box 1738, 3000 DR Rotterdam, The \\ Netherlands \\ ${ }^{\mathrm{d} C a t h o l i c ~ U n i v e r s i t y ~ o f ~ L e u v e n, ~ D e p a r t m e n t ~ o f ~ T r a n s p o r t a t i o n ~ P l a n n i n g ~ a n d ~ H i g h w a y ~ E n g i n e e r i n g, ~}$ \\ Kasteelpark Arenberg, 40, B-3001 Heverlee, Belgium
}

\begin{abstract}
The Dutch national road network has been developed over several decades. In the past, roads were constructed according to the then current spatial and transportation planning philosophies. Because the existing road network is a result of a long process of successive developments, the question can be asked whether this network is the most appropriate from the current point of view, especially taking in consideration the current socio-economic structure of the Netherlands. To answer this question an optimization algorithm for designing road networks has been developed. With this algorithm the Dutch road network has been redesigned based on minimization of the travel and infrastructure costs and by taking into account the socio-economic structure of the Netherlands. A comparison between the existing network and the new design shows that the redesigned Dutch national road network has significantly lower total costs than the existing road network. It is found that the construction of less roads with more lanes on different locations leads to a reduction of the total travel time and the total vehicles kilometers traveled.
\end{abstract}

Keywords: Network Design Problem; road network; Netherlands; redesign; scratch; motorway

\section{Introduction}

The Dutch national road network has been developed over several decades. In the past, roads were constructed according to the then current spatial and transportation planning philosophies. Because the existing road network is a result of a long process of successive developments, the question can be asked whether this network is the most appropriate from the current point of view, especially taking into account the current socio-economic structure of The Netherlands. To answer this question we redesigned the road network from the beginning, using the present socio-economic and spatial structure of the Netherlands as the starting point. The redesign shows the 'ideal' road network given certain economic objectives.

Figure 1 illustrates the significance of congestion on the Dutch national road network. This congestion leads both to annoyance and to direct costs, quantified in the order of 0.6 billion euros in 2002, and estimated as high as 1.7 billion euros in 2020 (AVV, 2004). The occurrence of a certain degree of congestion is optimal from an economic point of view, but most likely, with the same total lane length, the amount of congestion could be smaller if the structure of the network were different.

\footnotetext{
* Corresponding author: Address: TNO, Van Mourik Broekmanweg 6, P.O. Box 49, 2600 AA Delft, The Netherlands. Tel.: +31 1526968 27; Fax: +31 152696854

E-mail addresses: maaike.snelder@tno.nl, wagelmans@few.eur.nl, jeroen.schrijver@tno.nl, h.j.vanzuylen@citg.tudelft.nl, ben.immers@tno.nl
} 


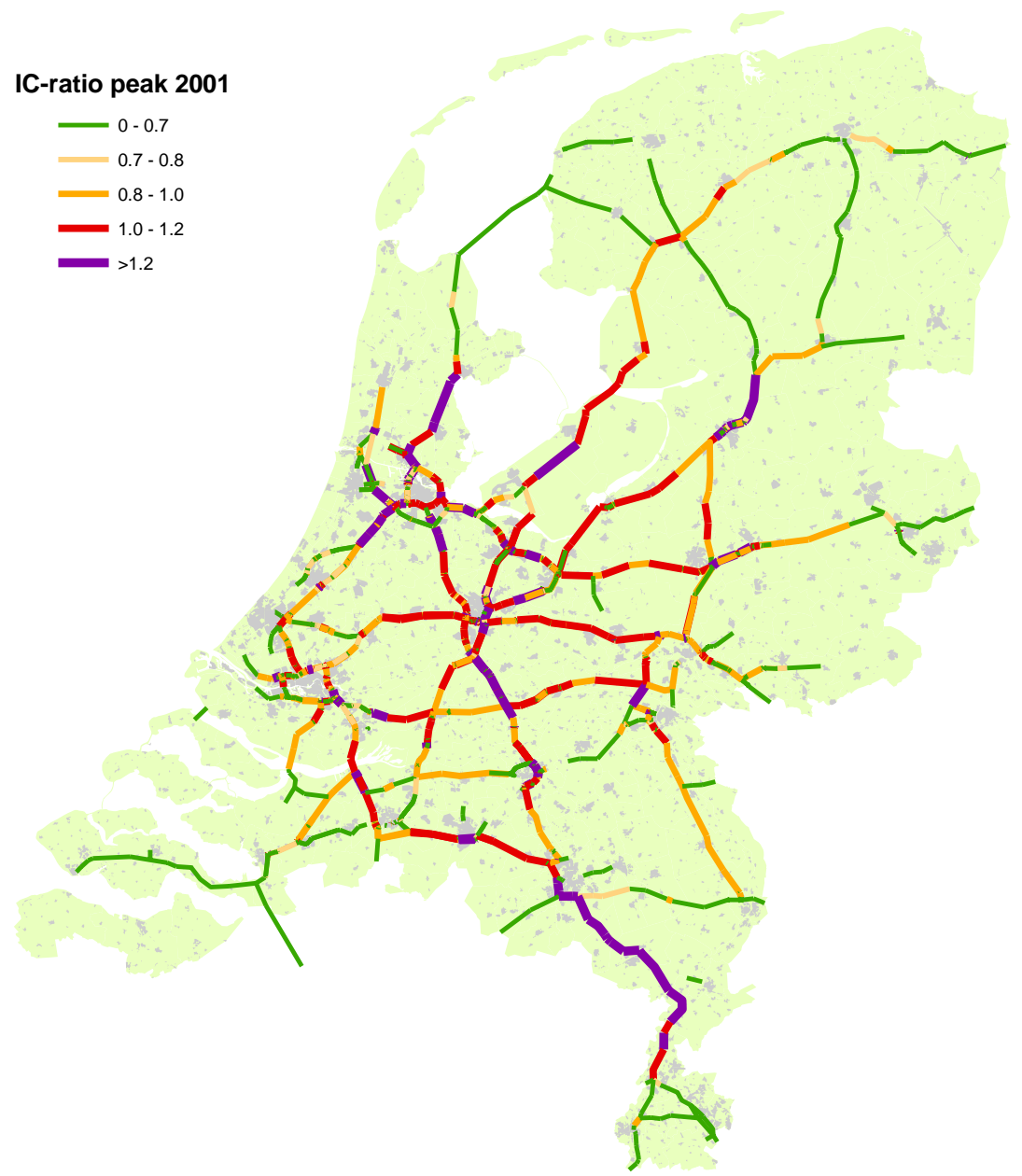

Figure 1: Intensity/Capacity ratio (IC-ratio) in the peak period on the motorways 2001

There is interaction between land use and infrastructure. On the one hand, the transport infrastructure is partly determined by the spatial structure, and, on the other hand, the (economic) spatial structure is partly determined by the transport infrastructure. The background between such interactions is that both persons and companies usually have a preference for settling at well accessible places, and that extra infrastructure is usually built at places were congestion is worst. Because the current socio-economic figures are taken as a starting point, it is likely that the 'ideal' road network resembles the current road network in many ways. However, there will also be differences. A comparison between this ideal network and the current road network gives an idea which locations in the current network should be improved in order to better deal with the demand for traffic. Besides, it could also show which network characteristics are optimal. For example, it could be used to answer questions like whether it is better to enlarge the capacity of existing roads or to construct entirely new roads. Or in other words: "Is it better to build two parallel roads with both two lanes or is it better to build one road with four lanes?”

It is very complex to design a road network starting from the beginning. Therefore, some simplifications are required. The main choice was to base the design method on the user optimum, which means that the resulting 'optimal' redesign of the Dutch road network is only optimal from the point of view of the costs for the road users. Only the costs of driving are taken into account. These costs consist of travel time costs (computed with an average value of time for passenger and 
freight transport), variable car/truck costs (for instance, fuel, tires, oil and maintenance), and infrastructure costs. External and environmental costs are only indirectly included. Land use is indirectly included in this study because the locations of both living areas and industrial and commercial areas determine travel demand. On the other hand, no extra costs are included for crossing rivers, lakes, and areas of ecological importance. Furthermore, the road network is only designed at a national and regional level. Local roads are not taken into account, although, obviously, in reality roads at all different levels should be complementary to each other. Finally, reliability of travel times is becoming an increasingly important issue. If the road network is designed in a robust way, this improves the reliability of travel times. However, the robustness of the network is not included in the applied optimization criteria. Still, we did compute the effects of an increase of the demand on the quality indicators (the indicators are described in section 4.1). This gives an impression of the robustness of the network with respect to variations in demand.

The Network Design Problem (NDP) and methods to solve this problem are presented in section 2. Section 3 describes the algorithm and its input, as used to make a redesign of the Dutch road network. In Section 4 the results are presented together with a comparison between the existing road network of the Netherlands (2001) and its redesign. Finally, section 5 contains the conclusions.

\section{Network Design Problem}

The problem of redesigning complete networks can be seen as a special case of the Network Design Problem (NDP). The NDP is a well known problem in the literature. It has been recognized as one of the most difficult and challenging problems in transport (Yang and Bell, 1998). The problem involves the optimal decisions on the expansion of a road network. Usually there is a certain budget restriction. The NDP can be formulated in a discrete and continuous way. The discrete version of the problem is a NP-complete problem (Johnson et al., 1978), which means that it is unlikely that the problem can be solved within polynomial computation time.

In different articles and books overviews are presented of methods that solve the NDP: (Magnanti and Wong, 1984), (Yang and Bell, 1998), (Steenbrink, 1974b). These overviews clearly show that there are a many possible methods. Although the methods differ in many ways they also have a number of similarities. For example, the NDP is usually formulated as a bi-level problem. The top level addresses the question where new links should be constructed or where the capacity of existing roads should be extended given the transport flows. The objective function on this level considers the total costs of road investments and the travel costs. The lower level problem is the assignment problem. In the assignment problem the traffic is assigned to the network, where the objective function considers the individual travel time. This bi-level problem can be seen as a Stackelberg game, in which the network designer (on the top level) is the leader and the travelers (at the lower level) are the followers.

The bi-level problem can be solved in different ways. The existing approaches for solving the upper level problem can be divided into three groups. The first group is the group of the discrete and exact approaches. In LeBlanc (1975) a Branch and Bound algorithm is used and in Poorzahedy and Turnquist (1982) a Branch and Backtrack algorithm is used for solving an approximation of the NDP. The second group is the group of the discrete and heuristic approaches. In Xiong and Schneider (1992) a cumulative genetic algorithm is used. The third group contains the continuous and heuristic approaches. These approaches are used most frequently. For example, in Pearman (1979) a very simple approximation method is used. Steenbrink (1974a and 1974b) uses a decomposition method. In Friesz et al. (1992) simulated annealing is used and in Abdulaal and LeBlanc (1979) the methods of Hooke and Jeeves and Powell are used. The method of Fibonacci, Golden section and Bolzano search are applied in Suwansirikul et al. (1987). They show that this algorithm is faster than the algorithm of Hooke and Jeeves in case of convex investment functions.

The lower level problem can be solved by different types of assignments. Choices have to be made between static and dynamic assignments, between deterministic or stochastic assignments, between 
single user or multi user class assignments and a decision has to be made as to whether or not an equilibrium assignment is used. In Ortúzar and Willumsen (2001) the different assignment methods are described in detail. In previous research all kinds of assignment methods are used for solving the lower level problem of the NDP. For example, in Friesz et al. (1992) and LeBlanc (1975) the FrankWolfe algorithm is used to carry out a deterministic user equilibrium assignment. In Xiong and Schneider (1992) a neural network approach is used to carry out this same assignment. The stochastic user equilibrium assignment is used in Lo and Tung (2001). In Davis (1994) and Chen and Alfa (1991) this kind of assignment is used in combination with respectively the continuous and discrete version of the NDP.

\section{Complete redesign of road networks}

In this study a method was developed and implemented for the complete redesign of road networks, that is, taking the imaginary situation as a starting point where land use exists, however, without any road network present. This method was tested by designing a road network for The Netherlands which minimizes the costs of the drivers given the current-socio economic situation. For that case, in this chapter an adjusted formulation of the NDP is presented.

An iterative optimization-assignment (IOA) algorithm was used that iteratively solves the upper and lower level problems. It was chosen to use a continuous formulation of the NDP. In the continuous NDP formulation capacities can take all values larger than or equal to $0 \mathrm{pcu} /$ hour (passenger car units per hour). In contrast, in practice the capacity can only take a limited number of values, dependent on the number of lanes, road type and the maximum speed. For this, a discrete formulation of the NDP appears the more appropriate. However, the discrete decision version of the problem is a NP-complete problem (Johnson et al., 1978). This implies that the optimization version of the discrete NDP is NP-hard. Thus, a continuous formulation of the NDP (also called mixed continuous formulation (Yang and Bell, 1998)) is required, certainly for the design of large networks. The method of Golden section search (Press et al., 1999) was used to compute the optimal link capacities (upper level) given the flows on each link.

An all or nothing (AON) assignment was used in the lower level problem. In this assignment method all travelers choose the route with the lowest generalized travel cost, and congestion is not taken into account. It is clear that this type of assignment does not describe the route choice of travelers in reality too well. However, for our network design problem this assignment algorithm is the most suitable: it is very fast and, more importantly, assigns the travelers to the routes that are preferred in the non-congested situation and avoids that cut-through routes are unnecessarily created. The aim is to redesign the Dutch road network in such a way that the preferences of travelers are taken into account in a satisfactory way. This implies that the network is to be adjusted to the preferences of travelers. Because road users prefer traveling via the shortest/fastest/cheapest route, an all or nothing assignment is the appropriate assignment method in the design phase (if the network is designed from the beginning). It could be argued that this assignment results in a situation with congestion and thus, that some travelers could be better off by using other routes. However, since in the next iteration the capacities are adjusted to the flows, the congestion is reduced to an economically optimal level. In the evaluation phase (after the design phase has been completed) a deterministic user equilibrium assignment is used to assess the quality of the network. An accurate assessment of congestion effects requires a dynamic traffic assignment with dynamic demand profiles. This study, however, did not have the ambition to go into so much detail. The objective was to determine the optimal road structure within a well defined, but still limited framework.

In this section the design method is described in detail. First, the applied notation is presented, thereafter the input is discussed, and finally a mathematical formulation of the upper and lower level problem is presented.

\subsection{Notation}

The following notation will be used in the remaining sections: 


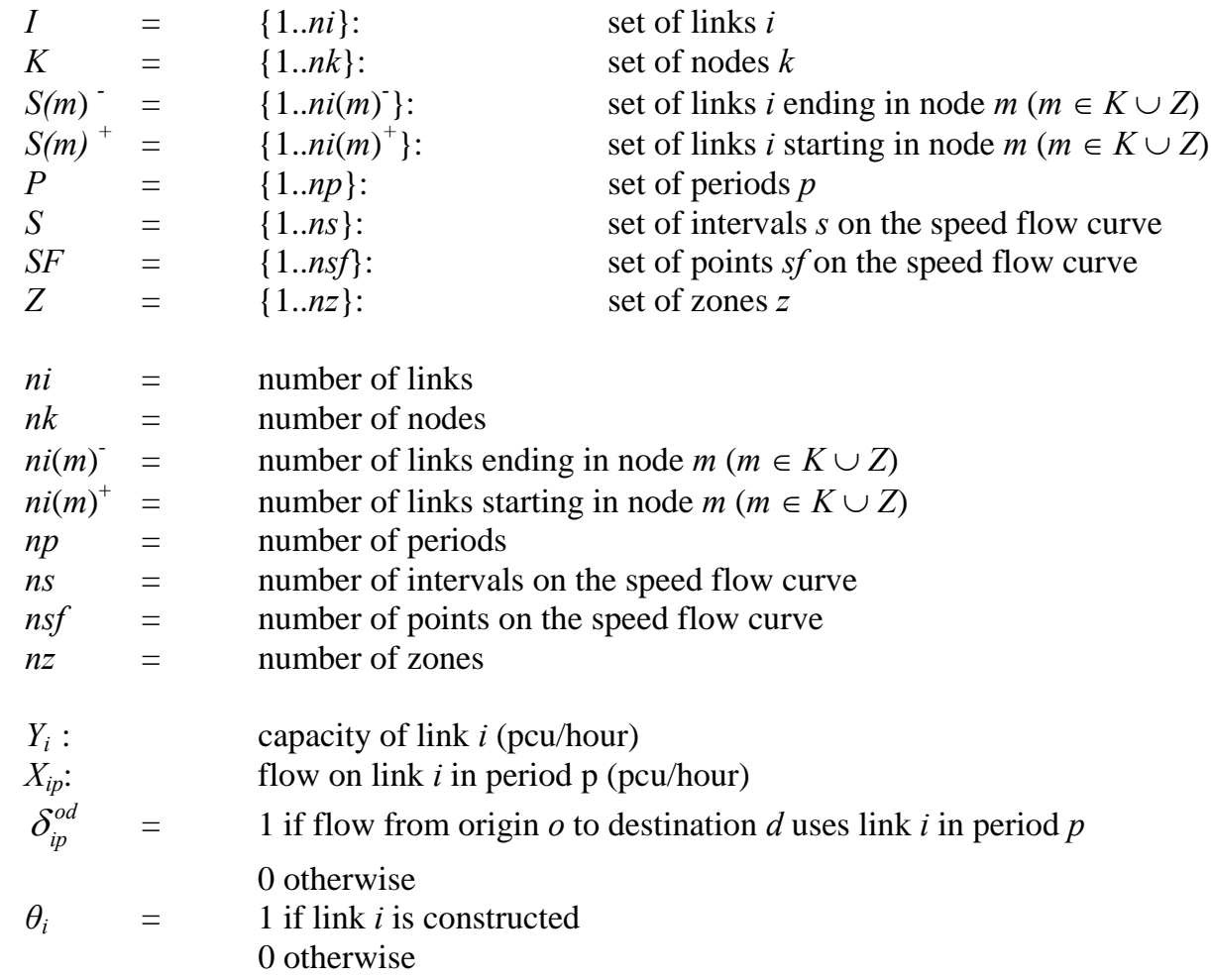

\subsection{Network}

A road network consists of access and egress nodes, links and junctions. Access and egress nodes are places where travelers or freight can enter or leave the network. Junctions are locations where two or more links come together. Links are connections between two access or egress nodes, between two junctions or between access or egress nodes and junctions.

The design of networks raises the following questions:

1 How many access or egress nodes should the network contain and where should these nodes be located?

2 how many junctions should the network contain and where should these junctions be located?

3 what must be the road type of the links?

4 which capacity is required for each of the links which connect the nodes and access or egress nodes?

There are many possible answers to these questions. We have chosen to use a grid as a starting point. A part of this grid is shown in figure 2. It contains almost 30,000 links and about 5,000 nodes.

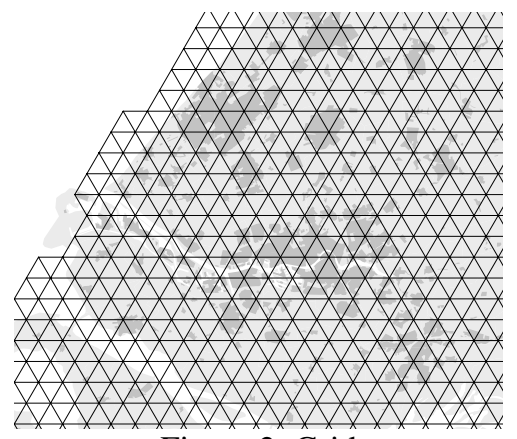

Figure 2: Grid 
The grid is built up from equilateral triangles with a horizontal orientation and with sides of 3 kilometers. Of course, the grid can be built up with other shapes like squares and the length of the links can also vary. However, triangles seem to be the best option since the number of links that come together in one node (6) is relatively large compared to other shapes. Furthermore, Bolt (1982) shows that the triangle structure has the highest capital costs (building costs) and the lowest variable costs (travel distances and travel time) compared to other shapes. For rich countries with a highly developed infrastructure network, like the Netherlands, this structure is probably the most suitable. Figure 3 shows the capital costs and variable cost for different network structures on a relative scale.

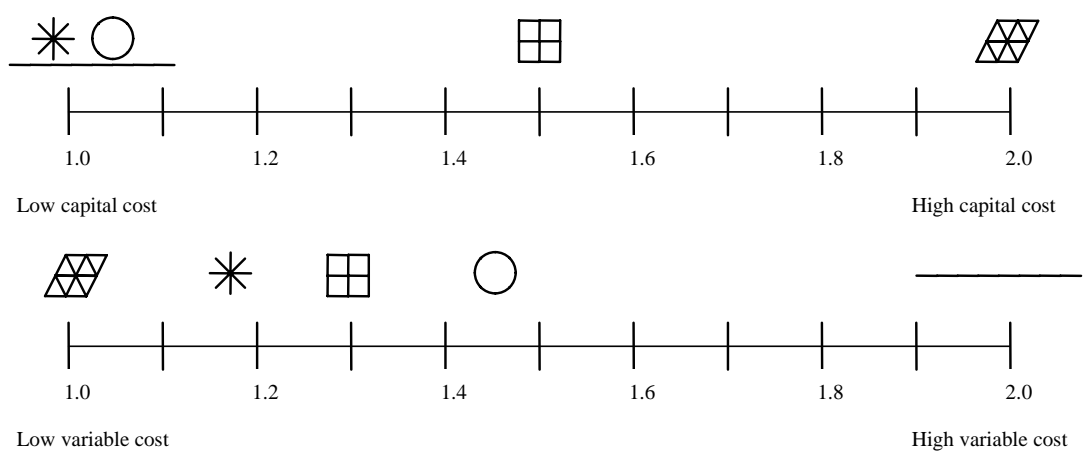

Figure 3: Capital cost and use cost for different network structures (Bolt, 1982)

The optimal distance for nodes of a network on a regional level is circa three kilometers (van Nes, 2002). Because this research focuses on the national level the distance of 3 kilometers is an appropriate lower bound for the distance between nodes. All the links in the grid can be used. Initially, all links are motorways with speeds according to the speed-flow curve of figure 5. The curve has been specifically fit to measured speeds on the Dutch motorways. The definitive choice of the infrastructure types for the links (regional road, trunk road or motorway with 2, 3, 4 or 5 lanes) depends on the final capacity of the links. In table 1 all the link types with their capacities are shown. The capacities are optimized during the designing process. If the capacity is larger than 0 passenger car units (pcu) per hour the link is included in the network.

Table 1: Capacity of roads per link type

\begin{tabular}{|c|c|c|}
\hline Link Type & Number of lanes & Capacity (y) (pcu/hour) \\
\hline Regional road & 1 & $0<\mathrm{Y} \leq 1000$ \\
\hline Trunk road & 1 & $1000<\mathrm{Y} \leq 1575$ \\
\hline Motorway & 2 & $1575<\mathrm{Y} \leq 4650$ \\
\hline Motorway & 3 & $4650<\mathrm{Y} \leq 7250$ \\
\hline Motorway & 4 & $7250<\mathrm{Y} \leq 9700$ \\
\hline Motorway & 5 or more & $\mathrm{Y}>9700$ \\
\hline
\end{tabular}

The SMART'99 zoning system (consisting of 500 zones) was used in this study. SMART (Schrijver, 2004) is a four stage transport model made and owned by TNO. It was applied in this research to create an OD matrix. Its zoning system as well as its assignment model (Smartass) were used. In figure 4 this zoning system is shown. The figure shows the number of inhabitants (12 years and older) per square kilometer. All the zones are connected to the nearest node in the grid by feeders. The locations where the feeders meet the network are the access or egress nodes. 


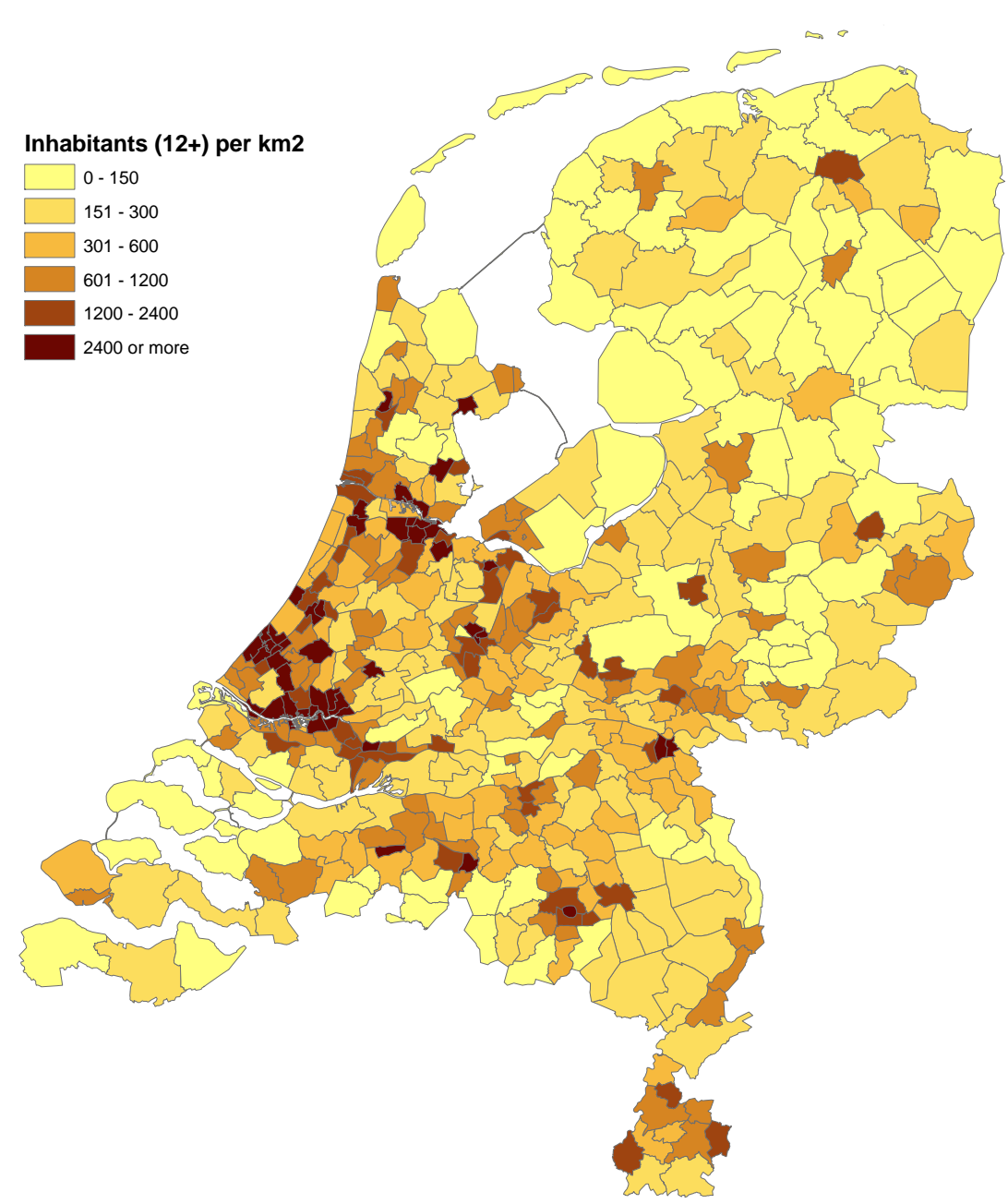

Figure 4: SMART’99 zoning system with population density

\subsection{Demand}

The optimal network depends on the demand for transport and the demand depends, in its turn, on the quality of the network. This implies that the optimal network structure and the demand should ideally be computed iteratively. However, the choice was made to use two fixed OD-matrices: OD2001 and OD-ideal. OD-2001 contains the demand for transport in the existing road network of the Netherlands of 2001 and OD-ideal represents the demand for transport in the ideal situation. Both matrices were constructed with SMART. OD-2001 is a result of a full model run for the year 2001. OD-ideal was constructed with almost the same input as is used for the construction of OD-2001 (same cost data, and socio-economic figures). The only difference is that the triangular grid network (with very large link capacities on all links) was used instead of the network of 2001. The shape of the grid network and the large link capacities ensure that the demand in OD-ideal is not limited by shortcomings of the network. OD-ideal contains all the trips that people would like to make and, therefore, it can be argued that the 'ideal' network should adjust to this demand and not the other way around. This approach compensates for the possible shortcomings of the use of a fixed OD matrix instead of elastic demand. However, induced demand, that is, demand created by changes in the socio-economic and spatial structure by another road infrastructure, was left out in this study.

OD-2001 and OD-ideal contain the same demand matrix for freight transport. This is in fact the existing demand for 2001. In the ideal case the freight volumes transported by road are probably higher. A generation model for freight transport is, however, not yet included in SMART and the 
increased freight transport was, consequently, not taken into account. Furthermore, OD-ideal was constructed with the existing network for public transport of 2001. Because the quality of the road network used to construct the matrix was very high, road transport had a more competitive position compared to public transport. The demand for public transport (and other modes) was, therefore, underestimated, and the demand for transport by car overestimated.

\subsection{Upper level problem: determining the optimal capacity of the links}

The objective of the main problem is shown in equation 1 . In the upper level problem the optimal capacities are determined by minimizing the total link costs $(t k)$ of the links given the flows of the previous assignment.

$\underset{Y, \theta}{\operatorname{MIN}} \sum_{i \in I} t k_{i}\left(X^{*}, Y_{i}, \theta_{i}\right)$

The costs of a link $i\left(t k_{i}\right)$ are computed as the product of the link length $\left(d_{i}\right)$ with the total costs per kilometer (travel time costs, variable vehicle costs, and infrastructure costs). The total variable vehicle costs and the total travel time cost are computed by multiplying the cost of traveling over the link for one user with the total number of users per week. In the formula below $p$ is the index for the different periods (off-peak, morning peak and evening peak), $w f_{p}$ is a parameter for the weight of a period in a week, $c a$ are the variable vehicle costs for a user, and $g_{i}$ is a function for the infrastructure costs.

$$
t k_{i}\left(X^{*}, Y_{i}, \theta_{i}\right)=d_{i}\left(\sum_{p}\left\{w f_{p} X_{i p}^{*}\left(t_{i p}\left(X_{i p}^{*}, Y_{i}\right)+c a\right)\right\}+g_{i}\left(Y_{i}, \theta_{i}\right)\right)
$$

The travel time costs for one user $\left(t_{i p}\right)$ for driving over a road of $1 \mathrm{~km}$ is computed by dividing the value of time of that user $(c t)$ by the realized speed on the link. The travel time costs vary per period and per link.

$$
t_{i p}\left(X_{i p}^{*}, Y_{i}\right)=c t /\left(v_{i p}^{s_{i p}\left(X_{i p}^{*}, Y_{i}\right)}\left(X_{i p}^{*}, Y_{i}\right)\right)
$$

The speed $\mathrm{v}_{\mathrm{ip}}^{\mathrm{s}_{\mathrm{p}}}\left(\mathrm{X}_{\mathrm{ip}}^{*}, \mathrm{Y}_{\mathrm{i}}\right)$ on link $i$ is a function of the capacity $Y_{i}$ and the flow $X_{i p}$. Figure 5 shows the speed flow curve that is used (SMART). Because all roads were assumed motorways during the design process only one curve was used. From this figure it can be seen that the curve consists of several parts. Within these parts the curves are linear. The total function is a continuous nondifferentiable function. If the part in which an IC-ratio lies is known, the accompanying speed can be computed with equation 4 . The part in which the IC-ratio lies can be determined with equation 8 . The parameters $a, b$ and $c$ can be computed with equation 5, equation 6 and equation 7 . In these formulas $s p_{s f}$ is the speed on point $s f$ of the curve and $i c_{s f}$ is the IC-ratio on point $s f$ of the curve. 


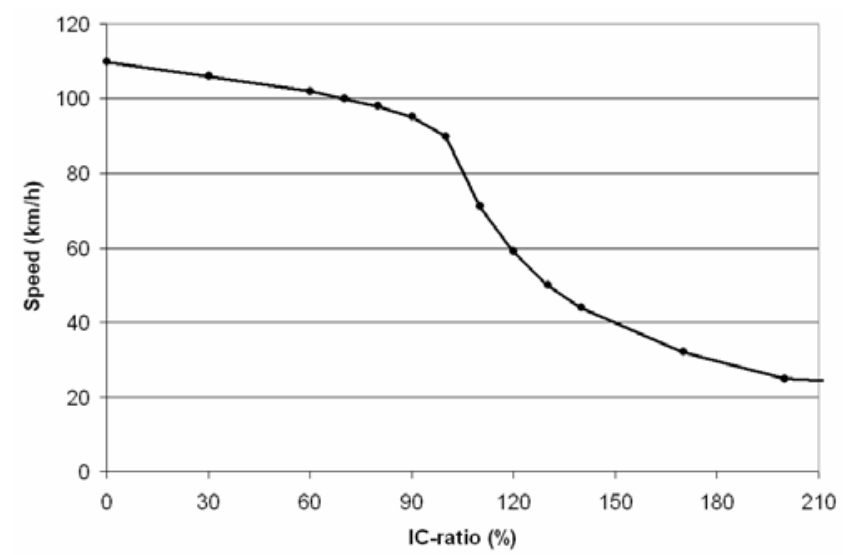

Figure 5: Speed flow curve

$$
\begin{aligned}
& v_{i p}^{s_{i p}\left(X_{i p}^{*}, Y_{i}\right)}\left(X_{i p}^{*}, Y_{i}\right)= \\
& \begin{cases}10^{-12} & \text { if } s_{i p}\left(X_{i p}^{*}, Y_{i}\right)=0 \\
\min \left(a_{s_{i p}\left(X_{i p}^{*}, Y_{i}\right)}+b_{s_{i p}\left(X_{i p}^{*}, Y_{i}\right)}\left(X_{i p}^{*} / Y_{i}-c_{s_{i p}\left(X_{i p}^{*}, Y_{i}\right)}\right), 10^{-2}\right) & \text { if } \quad s_{i p}\left(X_{i p}^{*}, Y_{i}\right) \in 1 . . n s\end{cases}
\end{aligned}
$$

The values of $10^{-12}$ and $10^{-2}$ were chosen in such a way that the speeds are also well defined for high and negative IC-ratios.

$$
\begin{aligned}
& a_{s_{i p}\left(X_{i p}^{*}, Y_{i}\right)}=s p_{s_{i p}\left(X_{i p}^{*}, Y_{i}\right)} \\
& b_{s_{i p}\left(X_{i p}^{*}, Y_{i}\right)}=\left(s p_{s_{i p}\left(X_{i p}^{*}, Y_{i}\right)+1}-s p_{s_{i p}\left(X_{i p}^{*}, Y_{i}\right)}\right) /\left(i c_{s_{i p}\left(X_{i p}^{*}, Y_{i}\right)+1}-i c_{s_{i p}\left(X_{i p}^{*}, Y_{i}\right)}\right) \\
& c_{s_{i p}\left(X_{i p}^{*}, Y_{i}\right)}=i c_{s_{i p}\left(X_{i p}^{*}, Y_{i}\right)} \\
& s_{i p}\left(X_{i p}^{*}, Y_{i}\right)=\left\{\begin{array}{ll}
0 & \text { if } X_{i p}^{*} / Y_{i}<0 \\
s f & \text { if } i c(s f) \leq\left(X_{i p}^{*} / Y\right)<i c(s f+1)
\end{array} \quad \forall s f \in S F\right.
\end{aligned}
$$

The costs of infrastructure $g_{i}\left(Y_{i}, \theta_{i}\right)$ are also part of the total link costs $\left(t k_{i}\right)$. The costs of infrastructure consist of fixed and variable costs (equation 9). These costs only have to be paid if a link is constructed. That is, if $\theta_{i}$ is equal to 1 . Cic are the constant infrastructure costs and $c i v$ are the variable infrastructure costs. Initially, these costs were set to 4076 euro $/ \mathrm{km}$ per week and 1.31 euro/km per pcu per week (Meeuwissen, 2003). In a sensitivity analysis, the influence of these values is considered.

$g_{i}\left(Y_{i}, \theta_{i}\right)=\theta_{i} \operatorname{cic}+\operatorname{civ}\left|Y_{i}\right|$

Constraints

The flow on a link is the optimal flow of the previous assignment (equation 10).

$X^{*}=$ flow assignment 
A link is either constructed $\left(\theta_{i}=1\right)$ or not constructed $\left(\theta_{i}=0\right)$ (equation 11).

$\theta_{i} \in\{0,1\} \quad \forall i \in I$

The capacity of link $i$ can only be larger than 0 pcu/hour if the link is constructed. $\operatorname{Max} Y$ was given a very large value.

$Y_{i} \leq \theta_{i} \max Y \quad \forall i \in I$

\subsection{Lower level problem: assignment}

The objective of the assignment problem is shown in equation 13. The optimal link flows $(X)$ are determined by minimizing the costs per user (equation 14) given the capacities of the links. This is done with an AON-assignment. The formulation of the objective function and the restrictions presented in this section are only correct for this type of assignment.

$$
\operatorname{MIN}_{X} \quad \sum_{i \in I} \sum_{p \in P} l c_{i p}\left(X_{i p}, Y_{i}^{*}\right) X_{i p}
$$

The costs for one user for traveling over a link $l c_{i p}\left(X_{i p}^{*}, Y_{i}, \theta_{i}\right)$ are specified in equation 14. The route choice of travelers depends on the costs of each link. These costs consist of travel time costs (equation 3), variable vehicle costs $(\mathrm{ca}=0.11 \mathrm{euro} / \mathrm{km})$, infrastructure costs, extra costs (equation 15) and a penalty if a link exists in only one direction (equation 16).

$$
l c_{i p}\left(X_{i p}^{*}, Y_{i}\right)=d_{i}\left(t_{i p}\left(X_{i p}^{*}, Y_{i}\right)+c a+i n f r a_{i p}\left(X_{i p}^{*}, Y_{i}\right)+\operatorname{extra}_{i}\left(Y_{i}\right)+\operatorname{penalty}_{i}(Y)\right)
$$

In the current situation (also in the situation of 2001) the users of the roads have to pay a fixed car ownership tax every year and there is an excise on fuel consumption. These taxes are not directly related to infrastructure costs. Nevertheless, it was decided that in the redesign process the user has to pay for the infrastructure costs. In this way roads are only constructed if they are used by a sufficient number of travelers. Further, a large portion of the capacity is only used by a small group of users. This was taken into account by passing the costs of that 'extra capacity' only onto those travelers who actually use the capacity. That is, travelers in the off-peak period do not have to pay for the capacity that is only used in the peak period. This concept is presented in (Meeuwissen, 2003). A mathematical formulation for the computation of the infrastructure costs for one user, that is, $\operatorname{infra}_{i p}\left(X_{i p}^{*}, Y_{i}\right)$, as well as a more detailed description can be found in his paper.

As stated above some extra costs were included in the users cost function. These costs decrease if the link capacity increases. The function for the extra costs is shown in equation 15 . The extra costs were included to make sure that some concentration of links takes places. If these costs were not included many small roads would be constructed instead of a smaller number of more significant links. Concentration of traffic on links leads to a loss of directness in the connection of zones, but the advantages of concentration easily compensate for this. Concentration results in economies of scale. With the same total capacity concentration leads to better usage of the infrastructure, more efficient technologies can be used, and it results in less environmental damage (Bovy and Van Nes, 2002). The user does not really have to pay for these extra costs and, therefore, they were not included in the optimization of the link capacities. The parameters $w 1$ and $w 2$ were estimated based on the lower speeds, the higher risks of accidents and the higher variable car costs on roads of a lower level than a 
motorway. This results in values of 1000 and -1.3 for $w 1$ and $w 2$ respectively. These values are further considered in a sensitivity analysis.

$\operatorname{extra}_{i}\left(Y_{i}\right)=w 1 Y_{i}^{w 2}$

The OD-matrices do not have to be symmetrical, because it is, for example, possible to make a trip in one direction in the off-peak period and to make a return trip in the peak period. This can result in links that are only constructed in one direction. This is not desirable and, therefore, a penalty is included if a link exists in just one direction. The penalty is computed with equation 16.

penalty $_{i}\left(Y_{i}\right)=\left\{\begin{aligned} 10^{6} / Y_{i} & \text { if } Y_{i} \neq 0 \text { and the link in opposite direction does not exist. } \\ 0 & \text { otherwise }\end{aligned}\right.$

\section{Constraints}

The capacities of the links are the optimal capacities computed in the optimization of the upper level problem (equation 17). This means that $Y^{*}$ is fixed in the lower level problem.

$Y^{*}=$ optimal capacities

All the flows that enter a node also have to leave that node (equation 18).

$\sum_{i \in S(k)^{-}} \delta_{i p}^{o d}$ trips $_{\text {od }}=\sum_{i \in S(k)^{+}} \delta_{i p}^{o d}$ trips $_{\text {od }} \quad \forall k \in K, \forall o \in Z, \forall d \in Z, \forall p \in P$

The total flow that goes to centroid $z$ and comes from origin $o$ must be equal to the number of trips from origin $o$ to centroid $z$ (equation 19).

$$
\sum_{i \in S(z)^{-}} \delta_{i p}^{o z} \text { trips }_{o z}=\text { trips }_{o z} \quad \forall z \in Z, \forall o \in Z /(z), \forall p \in P
$$

The total flow that comes from centroid $z$ and goes to destination $d$ must be equal to the number of trips from centroid $z$ to destination $d$ (equation 20).

$$
\sum_{i \in S(z)^{+}} \delta_{i p}^{z d} \text { trips }_{z d}=\text { trips }_{z d} \quad \forall z \in Z, \forall o \in Z /(z), \forall p \in P
$$

The total flow on link $i$ in period $p$ must be equal to the sum of the trips on OD-relations that use that link in period $p$.

$$
X_{i p}=\sum_{o \in Z} \sum_{d \in Z} \delta_{i p}^{o d} \text { trips }_{o d} \quad \forall i \in I, \forall p \in P
$$

All trips from origin $o$ to destination $d$ either use (1) or do not use (0) link $i$ in period $p$.

$$
\delta_{i p}^{o d} \in\{0,1\} \quad \forall i \in I, \forall p \in P, o \in Z, d \in Z
$$




\section{Results}

This section presents the 'optimal' redesign of the Dutch road network. Because an iterative approach was used in combination with a numerical method (Golden section) to solve the main problem, the resulting network most likely represents not a global but a local optimum. The algorithm converges to this optimum in about 20 iterations. The question can be asked how close the resulting local optimum is to the global optimum. Usually this question is answered based on lower bounds. This approach is not followed in this paper because it appeared very difficult to find a lower bound of good quality. Another approach to get an impression of the quality of the design method is to compare the resulting network with networks designed with other methods. Besides the quality of the design method, the quality of the resulting networks is also important. In section 4.1 we describe the quality indicators that were used. In section 4.2 and 4.3 the current network and the 'optimal' redesign of this network are described together with their quality indicators. Finally section 4.4 gives a comparison between both.

\subsection{Network quality indicators}

Besides based on the total costs, the quality of a network can be measured with the following indicators:

- $\quad$ a measure for detours, in time and distance (Q)

$Q_{p}=\sum_{o \in Z} \sum_{d \in Z}\left(\right.$ trips $\left._{o d p} * d c f_{o d}\right) / \sum_{o \in Z} \sum_{d \in Z}\left(\right.$ trips $\left._{o d p} * t_{o d p}\right)$

In this formula $t_{o d p}$ is the realized travel time from origin $o$ to destination $d$ in period $p$ and $d c f$ is the direct distance (that is, in a straight line). $Q$ can take a maximum value of $110 \mathrm{~km} / \mathrm{h}$ (based on the speed flow curve of figure 5). Lower values (speeds) are caused by detours made in distance and delays (congestion). $Q$ must be computed separately for every time period $p$.

- $\quad$ vehicle kilometers traveled

Freight transport is included in the vehicle kilometers traveled, but the vehicle kilometers traveled by intra zonal traffic are not included in this indicator. One vehicle kilometer traveled by a truck counts for two. This means that the vehicle kilometers traveled are actually pcu kilometers traveled.

- total travel time

- $\quad$ speeds frequency table

The speed can be seen as an indicator for congestion. The lower the speed, the heavier the congestion. The level of the speeds and the number of links on which these speed levels occur can be read from a frequency table. The frequencies are only reported for speeds lower than 20, 50, 70, 80 and $100 \mathrm{~km} / \mathrm{h}$.

- $\quad$ total capacity and the total road length

- number of links. Because all links have a length of $3 \mathrm{~km}$ (with the exception of the Afsluitdijk and the Markerwaarddijk (figure 6)), this indicator is almost equal to the total road length. For clarity reasons both are computed.

Many of these indicators require that the intensities on the links are known. These intensities are computed with a deterministic user equilibrium assignment.

\subsection{Existing road network}

In this section we present the existing road network of the Netherlands in 2001 (as modeled in SMART) and its quality indicators. This is done to obtain an impression of the quality of the design method and to enable a comparison between the existing road network and its redesign. The indicators are computed for both the OD-matrix OD-2001 and OD-ideal. 
To ensure a fair comparison between the existing road network and its redesign, the indicators for the existing road network were computed under the assumption that all links in the existing network are motorways and thus have the same speed flow curve as used in this study. Table 2 shows all quality indicators for the total road length and capacity, while the same is shown graphically in Figure 6. This figure also contains information about the numbers and names of the Dutch roads. These will be used in the remainder of this paper.

Table 2: Quality indicators for road length and capacity for the existing road network of 2001

\begin{tabular}{|c|c|}
\hline Description & 12624 \\
\hline Number of links & 29 million \\
\hline Total capacity pcu/h & 13142 \\
\hline Total road length secondary roads $(\mathrm{km})$ & 8371 \\
\hline Total road length main roads $(\mathrm{km})$ & 347 \\
\hline Total road length motorways 1 lane $(\mathrm{km})$ & 4116 \\
\hline Total road length motorways 2 lanes $(\mathrm{km})$ & 642 \\
\hline Total road length motorways 3 lanes $(\mathrm{km})$ & 92 \\
\hline Total road length motorways 4 lanes $(\mathrm{km})$ & 2 \\
\hline Total road length motorways 5 lanes $(\mathrm{km})$ & \\
\hline
\end{tabular}

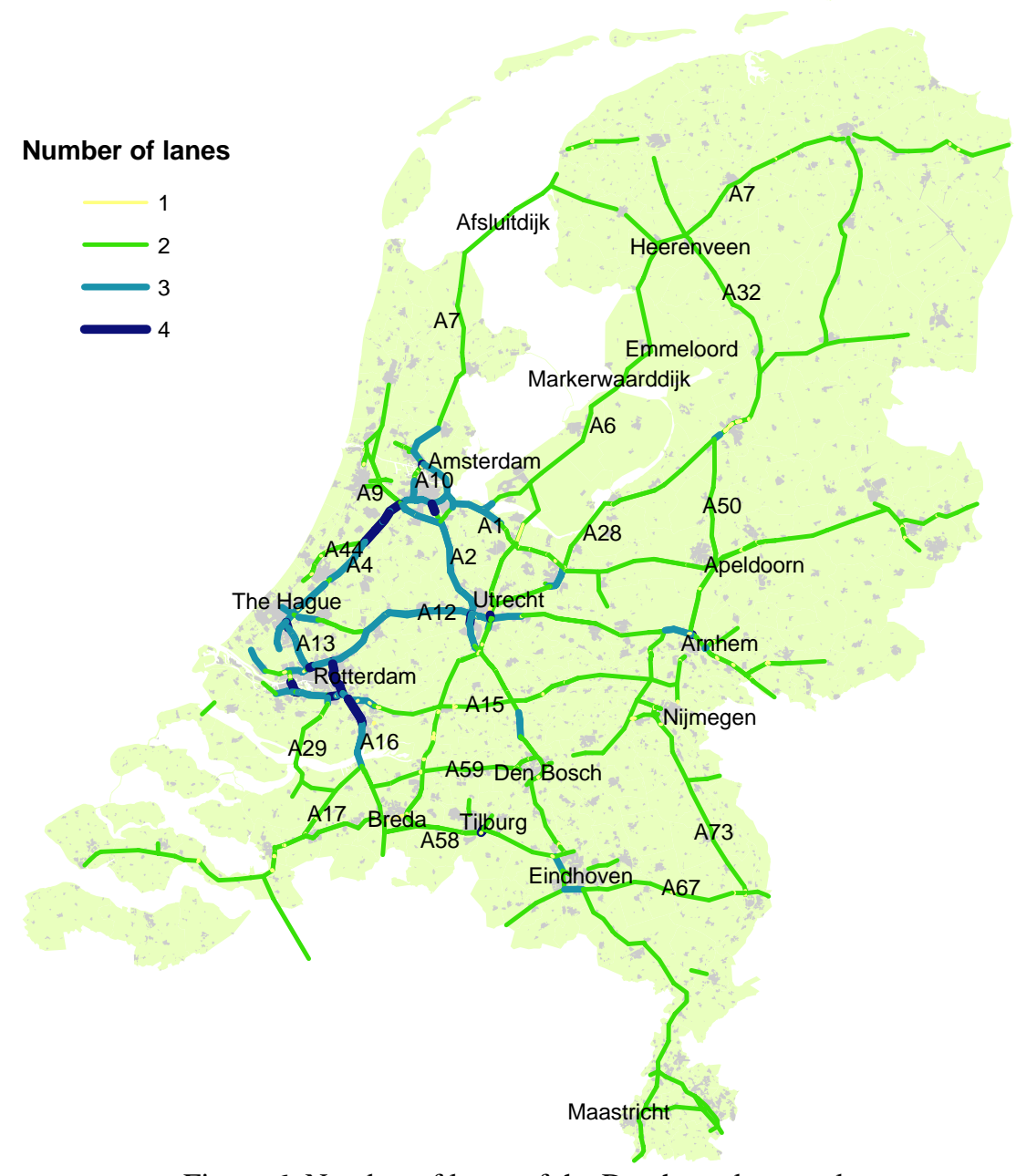

Figure 6: Number of lanes of the Dutch road network 
Table 3 contains all quality indicators with respect to the traveled kilometers. This table shows that all quality indicators are worse for OD-ideal than for OD-2001. The total travel time increases by a factor of 1.8 in the peak period and 1.5 in the off-peak period. The total vehicle kilometers traveled increases by a factor of 1.5 in the peak period and 1.3 in the off-peak period and for Q the increase is a factor of 1.3 in the peak period and 1.1 in the off-peak period. This indicates that the demand for travel in the current situation in the Netherlands has adjusted itself to the existing infrastructure.

Table 3: Quality indicators for traveled kilometers for the existing road network of 2001

\begin{tabular}{|c|c|c|c|c|c|c|}
\hline & \multicolumn{3}{|c|}{ OD-2001 } & \multicolumn{3}{c|}{ OD-ideal } \\
\hline & $\begin{array}{c}\text { Off- } \\
\text { peak } \\
\text { hour }\end{array}$ & $\begin{array}{c}\text { Morning } \\
\text { peak } \\
\text { hour }\end{array}$ & $\begin{array}{c}\text { Evening } \\
\text { peak } \\
\text { hour }\end{array}$ & $\begin{array}{c}\text { Off- } \\
\text { peak } \\
\text { hour }\end{array}$ & $\begin{array}{c}\text { Morning } \\
\text { peak hour }\end{array}$ & $\begin{array}{c}\text { Evening } \\
\text { peak } \\
\text { hour }\end{array}$ \\
\hline Q (km/h) & 66.9 & 62.0 & 61.9 & 59.6 & 48.0 & 47.8 \\
\hline Total travel time (hours x1 000) & 201 & 371 & 372 & 290 & 656 & 659 \\
\hline $\begin{array}{c}\text { Total vehicle kilometers } \\
\text { traveled (million km) }\end{array}$ & 18 & 31 & 31 & 24 & 45 & 45 \\
\hline
\end{tabular}

Table 4 shows the number of links with speeds lower than 20, 50, 70, 80 and $100 \mathrm{~km} / \mathrm{h}$. It appears that for the OD-2001 matrix even in the off-peak period low speeds are found for many links. These low speeds can in most cases be explained by the fact that many links have speed-limits lower than $110 \mathrm{~km} / \mathrm{h}$. Nevertheless, figure 1 shows high IC-ratios and, therewith, congestion on many motorways in the peak period. In the case of OD-ideal the speeds are even lower.

Table 4: Frequency table speed for the existing road network of 2001

\begin{tabular}{|c|c|c|c|c|c|c|}
\hline & \multicolumn{3}{|c|}{ OD-2001 } & \multicolumn{3}{c|}{ OD-ideal } \\
\hline & $\begin{array}{c}\text { Off- } \\
\text { peak }\end{array}$ & $\begin{array}{c}\text { Morning } \\
\text { peak }\end{array}$ & $\begin{array}{c}\text { Evening } \\
\text { peak }\end{array}$ & $\begin{array}{c}\text { Off- } \\
\text { peak }\end{array}$ & $\begin{array}{c}\text { Morning } \\
\text { peak }\end{array}$ & $\begin{array}{c}\text { Evening } \\
\text { peak }\end{array}$ \\
\hline Speed $<20 \mathrm{~km} / \mathrm{h}$ & 4 & 7 & 7 & 4 & 38 & 38 \\
\hline Speed $<50 \mathrm{~km} / \mathrm{h}$ & 82 & 390 & 361 & 219 & 1287 & 1239 \\
\hline Speed $<70 \mathrm{~km} / \mathrm{h}$ & 313 & 1005 & 936 & 639 & 2495 & 2493 \\
\hline Speed $<80 \mathrm{~km} / \mathrm{h}$ & 405 & 1260 & 1214 & 837 & 2989 & 2961 \\
\hline Speed $<100 \mathrm{~km} / \mathrm{h}$ & 1410 & 3272 & 3252 & 2292 & 5591 & 5523 \\
\hline
\end{tabular}

The total costs (travel time costs, infrastructure costs and variable vehicle costs) of this network in the case of OD-2001 and OD-ideal are respectively $\underline{798 \text { million euro/week and } 1096 \text { million }}$ euro/week. These total costs differ approximately $37 \%$.

\subsection{Redesign of the road network of the Netherlands}

To redesign the Dutch road network, the demand pattern OD-ideal was used, together with the following values for the parameters:

- fixed infrastructure costs (cic): 4076 euro/km per week (depreciation) (50\%, 110\%, 200\%, $300 \%)$

- variable infrastructure costs ( civ ): 1.31 euro/(pcu km) per week (50\%, 110\%, 200\%, 300\%)

- variable vehicle costs (ca): 0.11 (euro/(pcu $\mathrm{km}))(110 \%)$

- value of time (ct): 11.47 (euro/(pcu hour)) (110\%)

- parameter $w 1$ of extra costs function for concentration of links: 1000 (euro/(pcu km)) (2000, 3000)

- $\quad$ parameter $w 2$ of extra costs function for concentration of links: $-1.3(-1.1,-1.5)$

These values are estimations. It is possible that different values hold in reality than applied in this model approach. This is especially true for the parameters $w 1$ and $w 2$. A sensitivity analysis was carried out to further study this. The numbers between brackets show the percentage changes in costs, respectively the parameter values that were used in the sensitivity analysis. Besides the costs and parameters above we also increased the demand for transport with $10 \%$ on all relations without 
redesigning the network. This gives a first impression of the robustness of the network. In the evaluation of the different designs, the total costs of each design were computed with the original settings of the costs. The total costs are the costs as defined in the objective function of the upper level problem. The conclusions from the sensitivity analysis are presented below.

The sensitivity analysis shows that changes of the parameters of the extra cost function for concentration have the largest effects on the network structure and the total costs. The maximum difference in the total cost compared to the network with the lowest costs is $2.3 \%$. Furthermore, there is an enormous difference in the number of links and, therewith, the geographical density of the roads in the designs with different parameters for the extra cost function. For example, a change of $w 2$ from -1.3 to -1.1 leads to a decrease in the number of links of $22.9 \%$ and a change of $w 2$ from 1.3 to -1.5 leads to an increase of the total number of links of 33.0\%. The total capacity shows much less variation (maximum of 13.7\%). From the sensitivity analysis it becomes clear that overall the indicators for the network designed with $w 1$ and $w 2$ respectively equal to 1000 en -1.3 give the lowest total cost. Consequently, the network presented as the 'optimal' redesign in this article is the network designed with parameters 1000 en -1.3 .

Variation of the fixed and variable infrastructure costs showed a maximum deviation of 2.2\% in the total costs and a maximum deviation of $2.3 \%$ in the indicators for the traveled kilometers. From this we conclude that the design algorithm is insensitive to changes in the fixed and variable costs. A similar conclusion can be drawn for the value of time and the variable vehicle costs.

An increase in the demand with $10 \%$ (without changing the design of the network) results in an increase of the total travel time of $10 \%$ in the off-peak period and $13 \%$ in the peak period. The total vehicle kilometers traveled increase with $9.8 \%$ in the off-peak period and with about $10.2 \%$ in the peak periods. There are two possible explanations for the small increase in travel time. The first explanation is that the model does not take congestion related effects like a capacity drop and blocking back effects into account. These effects could result in larger travel time increases. The robustness of the network (or the redundancy in the network) is the second explanation. The small increase in travel time implies that the designed network is capable of dealing with an increase in the demand and, therefore, is quite robust. However, the number of links with speeds lower than 70, 80 and $100 \mathrm{~km} / \mathrm{h}$ almost doubled and Q decreased with $0.2 \%$ in the off-peak period and $2.6 \%$ in the peak period. This means that a further increase in the demand probably causes more important performance decreases.

Finally, the sensitivity analyses showed that the 'optimal' network found by the applied design algorithm had the lowest total cost (computed with the identical cost parameters) of all networks designed in the sensitivity analysis. If the optimum found by the algorithm is a local optimum instead of a global optimum then it is likely that a change in one of the costs would result in a network with lower total costs. This does not prove that the algorithm actually found the global optimum, but it does imply that the solution found is likely to be a good one.

In figure 7 the 'optimal' redesign is shown. This network is designed based on optimization of the costs mentioned before. The three most remarkable characteristics of this network are the large number of lanes of different roads compared to the present situation, the many route alternatives and the absence of the Afsluitdijk. The quality indicators for this network are shown in the tables 5, 6 and 7. In the following section a comparison between the existing road network of 2001 and its redesign is presented. 


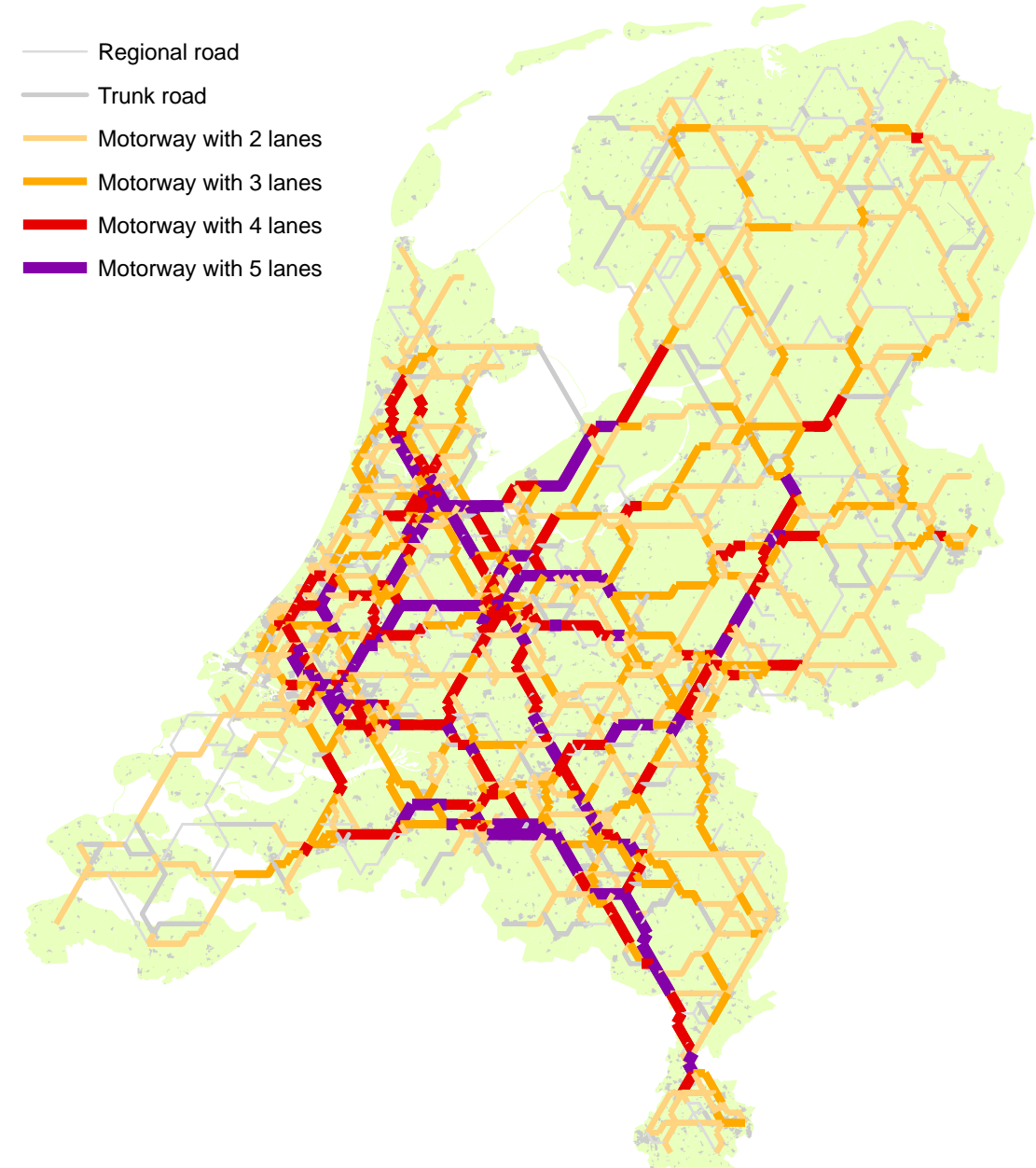

Figure 7: Redesigned Road network for the Netherlands

Table 5: Quality indicators for road length and capacity for the redesigned road network

\begin{tabular}{|c|c|}
\hline Description & \\
\hline Number of links & 5328 \\
\hline Total capacity pcu/h & 62.5 million \\
\hline Total road length regional roads $(\mathrm{km})$ & 2390 \\
\hline Total road length trunk roads $(\mathrm{km})$ & 1583 \\
\hline Total road length motorways 2 lanes $(\mathrm{km})$ & 7038 \\
\hline Total road length motorways 3 lanes $(\mathrm{km})$ & 2642 \\
\hline Total road length motorways 4 lanes $(\mathrm{km})$ & 1417 \\
\hline Total road length motorways 5 lanes $(\mathrm{km})$ & 973 \\
\hline
\end{tabular}

Table 6: Quality indicators for traveled kilometers for the redesigned road network

\begin{tabular}{|c|c|c|c|}
\hline & \multicolumn{3}{|c|}{ OD-ideal } \\
\hline & Off-peak hour & $\begin{array}{c}\text { Morning peak } \\
\text { hour }\end{array}$ & $\begin{array}{c}\text { Evening peak } \\
\text { hour }\end{array}$ \\
\hline $\mathrm{Q}(\mathrm{km} / \mathrm{h})$ & 68.0 & 65.6 & 65.6 \\
\hline Total travel time (hours x1000/week) & 254 & 480 & 480 \\
\hline $\begin{array}{c}\text { Total vehicle kilometers traveled (million } \\
\mathrm{km} / \mathrm{h})\end{array}$ & 22.3 & 40.6 & 40.6 \\
\hline
\end{tabular}


Table 7: Frequency table speed for the redesigned road network

\begin{tabular}{|c|c|c|c|}
\hline & \multicolumn{3}{|c|}{ OD-ideal } \\
\hline & Off-peak & Morning peak & Evening peak \\
\hline Speed $<20 \mathrm{~km} / \mathrm{h}$ & 0 & 0 & 0 \\
\hline Speed $<50 \mathrm{~km} / \mathrm{h}$ & 0 & 5 & 7 \\
\hline Speed $<70 \mathrm{~km} / \mathrm{h}$ & 4 & 124 & 124 \\
\hline Speed $<80 \mathrm{~km} / \mathrm{h}$ & 10 & 258 & 256 \\
\hline Speed $<100 \mathrm{~km} / \mathrm{h}$ & 158 & 2065 & 2044 \\
\hline
\end{tabular}

\subsection{Comparison with the current network}

In this section a comparison is made between the existing road network of 2001 of the Netherlands and its redesign. The comparison is based on the quality indicators and on the structure of the networks. The ten most remarkable similarities and differences in structure are presented.

A comparison between the quality of two networks can only be made if identical input is used. We decided to compare the networks designed with OD-ideal. It seems unfair to use OD-ideal for computing the indicators of the existing network because in reality a much smaller number of trips was made in 2001. However, in 2001 latent demand existed. A far larger number of trips would have been made by car if the quality of the existing network had been better. In contrast to OD-2001, ODideal does contain these trips and this matrix is therefore used in the comparison.

The total travel costs of the existing network are 1096 million euro/week and the travel costs of the redesigned network are 972 million euro/week. This means that the costs of the existing network could be improved by at least $11 \%$. The total road length of the existing network as modeled in SMART is 27 thousand $\mathrm{km}$ with a total capacity of 29 million pcu/hour (table 2). The redesign has a total road length of 16 thousand $\mathrm{km}$ with a total capacity of 62.5 million pcu/hour. Of course, the road length depends heavenly upon the design level, so a comparison of the road length only is not very meaningful. However, in combination with the total capacity it indicates that the roads in the redesign have much more lanes/capacity than the roads in the existing network. This can also be concluded from the total road length per road type. For example, the existing road network contains $736 \mathrm{~km}$ of roads with 3 or more lanes and the redesign contains about $5000 \mathrm{~km}$ of roads with 3 or more lanes. Furthermore, in the redesign the total vehicle kilometers traveled and the total travel time are respectively $8 \%$ and $17 \%$ less than the total vehicle kilometers traveled and the total travel time in the existing network. Overall, the conclusion is that the indicators of the redesigned network are significantly better than the indicators of the existing network. This implies that the redesigned network is better suited to the demand for travel by car.

The structure of the redesigned network does not differ that strongly from the existing road network. This was to be expected because of the interdependency between the infrastructure and the spatial structure (section 1). However, a closer look at both networks does show some differences. Below, the ten most remarkable similarities and differences (in random order) between the existing network of 2001 and its redesign are presented.

1) Ring roads around cities are not found in the redesign. The number of regions (zones) used and the lengths of the links in the grid should contain enough detail to make it possible that ring roads result from the design process. In the existing network the cities of Amsterdam (figure 8), Rotterdam and Eindhoven have complete or partial ring roads. Ring roads are often built for reasons of livability. Local authorities and citizens have a strong aversion of heavy traffic streams through their cities. In this study, the livability aspect is not explicitly included in the cost functions and, therefore, ring roads do not occur in the redesign,

2) the Afsluitdijk is not included in the redesign. The Afsluitdijk was constructed for hydraulic reasons and not for means of accessibility. Nevertheless, about 8300 travelers make use of 
this road every day. In the redesign, these travelers have to use the Markerwaarddijk or drive completely around the lake (IJsslemeer) (figure 8),

3) the A6 (figure 8), the road from Amsterdam to the north-east provinces, appears both in the existing network and its redesign. The first difference is that in the redesign this road splits at Emmeloord into two separate smaller roads, while in the existing network this road leads all the way to Heerenveen (about $45 \mathrm{~km}$ further to the North). The second difference is that the road consists of 4 to 5 lanes in the redesign while it only consists of 2 lanes in the original network. This is, partly, a consequence of the fact that the Afsluitdijk is not used in the redesign,

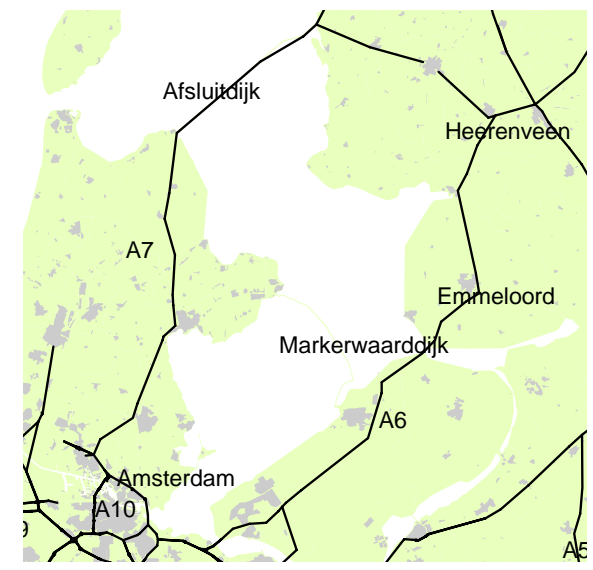

Figure 8: The ring road of Amsterdam, the Afsluitdijk, the Markerwaarddijk and the A6

4) in the existing network the two economically most important cities of the Netherlands (Amsterdam and Rotterdam) are not directly connected. To travel from Rotterdam to Amsterdam or the other way around, the available route is from the A13 from Rotterdam to The Hague and then the A4 from The Hague to Amsterdam (figure 9). In the 1960's the government started the construction of the A3, which was supposed to connect Amsterdam and Rotterdam directly. Soon thereafter this project was stopped because in the end the government decided to preserve the existing landscape. In the redesign the road from Rotterdam to Amsterdam does exist,

5) in the existing network Amsterdam is connected with The Hague by two motorways (figure 9): the A4, and to the west the A44. The A44 begins a little to the north of The Hague and joins the A4 about 15 to $20 \mathrm{~km}$ from Amsterdam. This situation makes it difficult to reach coast places (such as, Katwijk and Noordwijk) when they are approached from the southern/eastern origins. This is caused by the fact that the A4 is only linked to the A44 by a regional road through Leiden and another regional road in between The Hague and Leiden. In the redesign the main motorway connecting The Hague and Amsterdam is located close to the A4. The difference is that there are many parallel roads and that these roads are intertwined at many places. This implies that there are many alternative routes to travel between Amsterdam and The Hague and even Rotterdam. This illustrates one of the most important differences between the existing road network and its redesign: between the big cities there is a second coherent road network which is complementary to the main motorway network,

6) the A13 is in the existing road network the only motorway that connects Rotterdam and The Hague. This motorway is one of the most congested motorways in the Netherlands, especially in the direction from The Hague to Rotterdam. The construction of a second motorway (A4) south-west of the A13 has been planned for many years, but it is not clear when (if ever) the construction will start. In the redesigned network the A13 can be recognized with another motorway running parallel (about 5 kilometers to the south-west): this is the missing part of the A4. It runs from Delft to SchiedamlVlaardingen (smaller 
suburbs of Rotterdam on the west side). Surprisingly, the part of the A4 that exists in the current situation (from The Hague to Delft) is not part of the redesign (figure 9),

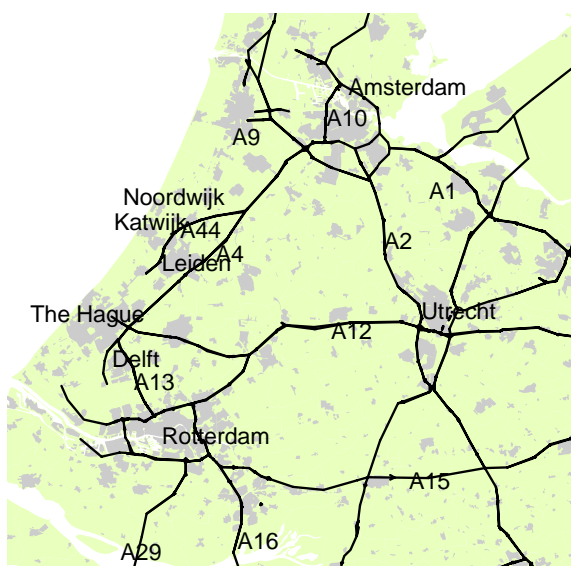

Figure 9: Connection between Amsterdam, Rotterdam, The Hague and Utrecht

7) the largest cities of the Netherlands (Amsterdam, The Hague, Rotterdam, Utrecht, Den Bosch, Eindhoven, Tilburg, Breda, Nijmegen and Arnhem) are connected by motorways with 4 or 5 lanes per direction. In the existing road network this is not the case: less lanes are available (figure 6). Motorways with 2x5 lanes hardly exist and motorways with 2x4 lanes are already quite exceptional. Even 6 lane motorways (3 per direction) are not common. In the existing road network roads of such significant dimensions are available only between Amsterdam, The Hague, Rotterdam and Utrecht,

8) in the existing road network there are two motorways that connect the northern part of the country (Friesland, Groningen and Drenthe) with the western part (A6/A7 and A28). The roads in the redesign do not match the existing network exactly, but the structure is more or less the same,

9) in the existing road network there are five main west to east connectors. The most northern connection runs from Amsterdam to Enschede (A1), the middle northern road (A12) from The Hague to Utrecht and Arnhem, the middle from the port of Rotterdam to Nijmegen (A15), the middle southern from Breda to Den Bosch (A59), and the most southern runs near the border between the Netherlands and Belgium (A58). In the redesign the A1, the A12 and the A59 can be recognized clearly. The A15 can also be distinguished, but it runs a slightly more southward. In fact, this motorway can be seen as a combination of the A15 and the A59 and A50 (the A59 and A50 are located parallel at the south of the A15),

10) the north-western part of the country is connected with the south-east by one long motorway in the existing network (A2). It starts in Amsterdam and goes all the way to the most southern part of Limburg. In the redesign this road is replaced by two parallel motorways, which consist of 4 and 5 lanes per direction from Amsterdam to Utrecht and surroundings. From there on, one of these motorways joins a motorway in the redesign road that is very similar to the A1. The other motorway continues in the south-eastern direction and is similar to the A2.

\section{Discussion, conclusion and recommendations}

Redesigning a complete network for an entire country is a complex task. Designing networks from the very beginning can be seen as a special case of the so-called Network Design Problem. This problem is complex even for small networks, let alone a network of about 30 thousand links, 5 thousand nodes and 500 zones. Furthermore, there are many actors involved, such as, travelers, local residents, and the government, all with different demands. Land use and the spatial structure are other key elements. On the one hand, they form a restriction for the locations available for the construction of infrastructure, and, on the other hand, there is a strong interaction between the 
locations where people live and enterprises operate, and the infrastructure. Finally, many factors should be included in the optimization process. There are costs directly related to traveling by car, but there are also external costs.

It is very difficult to take into account all the factors mentioned above. Therefore, some simplifications are required. When the 'optimal' redesign presented in this paper is considered, these simplifications have to be kept in mind. Nevertheless, it appears possible to meaningfully compare the existing road network with its redesign. The redesign shows that the current road network can be improved. The redesign of the Dutch national road network has significantly lower total costs than the existing road network (11\% lower). The total vehicle kilometers traveled and the total travel time are respectively $8 \%$ and $17 \%$ lower than in the existing network. This is realized through the construction of roads with more lanes and located somewhat differently, and through the construction of a second coherent road network which is complementary to the main motorway network between the major cities.

A sensitivity analysis showed that especially the parameters of the function that determines the concentration of roads have important impacts on the structure of the designed network. The total costs showed a variation of $2.3 \%$ in different runs and a variation of about $30 \%$ in the number of links constructed. The algorithm appears to be insensitive to changes in the fixed and variable infrastructure costs and to changes in the variable vehicle costs and the value of time. Furthermore, the 'optimal' redesign of the Dutch road network is robust in the sense that it is capable of dealing with an increase in demand of $10 \%$. This increase does not significantly influence the travel time of individual travelers and their vehicle kilometers traveled.

On the basis of the infrastructure network redesign effort, the following recommendations follow:

- Environmental issues, land use and safety play an important role in the decisions on new roads or extra lanes, and, therefore, these aspects should be taken into account more explicitly. This could for example be done by extending the objective functions or by making the infrastructure costs dependent upon the location,

- the existing road network is not used as a factor in the design method. Although the redesign of the complete network gives an impression of the main opportunities for improvement of the current network, it is not sufficiently specific for decision makers. A possibility is to adjust the design algorithm in such a way that it can take the existing road network into account and compute the most valuable improvements of the existing network,

- the demand matrix OD-ideal is suitable for the design of the 'ideal' road network when a situation without existing infrastructure is taken as the basis, but it is advisable to make the design algorithm capable of dealing with elastic demand (demand that depends upon the quality of the network). This is necessary to model small changes to existing networks,

- the OD-matrices that are used to redesign the Dutch road network do not contain international traffic. Off course, the capacity of roads in the Netherlands of international importance depends also on international traffic. Therefore, international traffic should be included in the ODmatrices,

- finally, the reliability of travel time needs to be taken into account in future research. The reliability of travel time is a complicated term because it is influenced by many factors and many indicators can be used to measure reliability. The robustness of the network is one of the factors of influence. Future research could show if it is possible to take robustness and/or reliability into account in the design phase. The implementation of this improvement and the improvements mentioned above is not easy, because it requires more sophisticated route choice algorithms. 


\section{Acknowledgments}

We are very grateful for the contribution of Hans Meeuwissen. Unfortunately, he is not with us any more, but his ideas and his enthusiasm have been a source of inspiration and have clearly influenced the outcomes of our research. We also thank Minwei Li for his comments on this paper.

\section{References}

Abdulaal, M., LeBlanc, L.J. (1979) Continuous Equilibrium Network Design Models. Transportation Research B, Vol. 13B, No. 1, pp 19-32

AVV (2004) Fileverkenning, de ontwikkeling van vertraging op het Nederlandse autosnelwegennet. Adviesdienst Verkeer en Vervoer, Directoraat Generaal Rijkswaterstaat, Ministerie van Verkeer en Waterstaat, Rotterdam, The Netherlands

Bolt, D. (1982) Urban Form and Energy for Transportation. TNO, Delft, The Netherlands

Bovy, P.H.L., van Nes, R. (2002) Ruimtelijke en Vervoersplanning. Technische Universiteit Delft, Faculteit Civiele techniek en Geowetenschappen, Sectie Verkeerskunde, deel B, september 2002

Chen, M., Alfa, A.S. (1991) A network design algorithm using a stochastic incremental traffic assignment approach. Transportation science, Vol. 25, No. 3

Davis, G.A. (1994) Exact local solution of the continuous network design problem via stochastic user equilibrium assignment. Transportation Research B, Vol. 28B, No.1, pp 61-75

Friesz, T.L., Cho, H., Mehta, N.J., Tobin, R.L., Anandalingam, G. (1992) A Simulated Annealing Approach to the Network Design Problem with Variational Inequality Constraints. Transportation Science, Vol. 26, No. 1, pp 18-26

Johnson, D.S., Lenstra, J.K., Rinnooy Kan, A.H.G. (1978) The complexity of the network design problem. Erasmus Universiteit Rotterdam, Econometrisch Instituut, report 7721/MO

LeBlanc, L.J. (1975) An Algorithm for the Discrete Network Design Problem. Transportation Science, pp 183-199

Lo, H.K., Tung, Y.K. (2001) Network Design for Improving Trip Time Reliability. Transportation research board, $80^{\text {th }}$ annual meeting, TRB ID: 01-2204

Magnanti, T.L., Wong, R.T. (1984) Network Design and Transportation Planning: Models and Algorithms. Transportation Science, Vol. 18, No. 1, pp 1- 48

Meeuwissen, A.M.H. (2003) Exchange between congestion cost and cost for infrastructure. Proceedings of the $19^{e}$ Dresden Conference on Traffic and Transport

Ortúzar, J., Willumsen, L.G. (2001) Modeling Transport. John Wiley \& Sons, Chichester

Pearman, A.D. (1979) The structure of the solution set to network optimization problems. Transportation Research B, Vol. 13B, No. 1, pp 81-90

Poorzahedy, H., Turnquist, M.A. (1982) Approximate algorithms for the discrete network design problem. Transportation Research B, Vol. 16B, No. 1, pp. 45-55

Press, W.H., Teukolsky, S.A., Vetterling, W. T., Flannery, B.P. (1999) Numerical Recipes in C, The Art of Scientific Computing. Second edition, Cambridge University Press, Cambridge. 
Schrijver, J.M. (2004) SMART@home 4.0 handleiding, TNO, Delft, The Netherlands, 04-7N07973401

Steenbrink, P.A. (1974a) Transport network optimization in the Dutch integral transportation study. Transportation research, Vol 8, pp 11-27

Steenbrink, P.A. (1974b) Optimization of Transport Networks. John Wiley \& Sons, New York

Suwansirikul, C., Friesz, T.L., Tobin, R.L. (1987) Equilibrium Decomposed Optimization: A Heuristic for the Continuous Equilibrium Network Design Problem. Transportation Science, Vol. 21, No. 4, pp. 254-263

van Nes, R. (2002) Design of multimodal transport networks, A hierarchical approach. TRAIL Research School, DUP Science, Delft

Xiong, Y., Schneider, J.B. (1992) Transportation Network Design Using a Cumulative Genetic Algorithm and Neural Network. Transportation research record 1364, pp 37-44

Yang, H., Bell, M.G.H. (1998) Models and algorithms for road network design, a review and some developments. Transport Reviews, Vol. 18, No. 3, pp. 257-278 


\section{Publications in the Report Series Research* in Management}

\section{ERIM Research Program: "Business Processes, Logistics and Information Systems"}

\section{5}

On The Design Of Artificial Stock Markets

Katalin Boer, Arie De Bruin and Uzay Kaymak

ERS-2005-001-LIS

http://hdl.handle.net/1765/1882

Knowledge sharing in an Emerging Network of Practice: The Role of a Knowledge Portal

Peter van Baalen, Jacqueline Bloemhof-Ruwaard, Eric van Heck

ERS-2005-003-LIS

http://hdl.handle.net/1765/1906

A note on the paper Fractional Programming with convex quadratic forms and functions by H.P.Benson J.B.G.Frenk

ERS-2005-004-LIS

http://hdl.handle.net/1765/1928

A note on the dual of an unconstrained (generalized) geometric programming problem

J.B.G.Frenk and G.J.Still

ERS-2005-006-LIS

http://hdl.handle.net/1765/1927

Privacy Metrics And Boundaries

L-F Pau

ERS-2005-013-LIS

http://hdl.handle.net/1765/1935

Privacy Management Contracts And Economics, Using Service Level Agreements (Sla)

L-F Pau

ERS-2005-014-LIS

http://hdl.handle.net/1765/1938

A Modular Agent-Based Environment for Studying Stock Markets

Katalin Boer, Uzay Kaymak and Arie de Bruin

ERS-2005-017-LIS

http://hdl.handle.net/1765/1929

Lagrangian duality, cone convexlike functions

J.B.G. Frenk and G. Kassay

ERS-2005-019-LIS

http://hdl.handle.net/1765/1931

Operations Research in Passenger Railway Transportation

Dennis Huisman, Leo G. Kroon, Ramon M. Lentink and Michiel J.C.M. Vromans

ERS-2005-023-LIS

http://hdl.handle.net/1765/2012

Agent Technology Supports Inter-Organizational Planning in the Port

Hans Moonen, Bastiaan van de Rakt, lan Miller, Jo van Nunen and Jos van Hillegersberg

ERS-2005-027-LIS

http://hdl.handle.net/1765/6636 
Faculty Retention factors at European Business Schools

Lars Moratis, Peter van Baalen, Linda Teunter and Paul Verhaegen

ERS-2005-028-LIS

http://hdl.handle.net/1765/6559

Determining Number of Zones in a Pick-and-pack Orderpicking System

Tho Le-Duc and Rene de Koster

ERS-2005-029-LIS

http://hdl.handle.net/1765/6555

Integration of Environmental Management and SCM

Jacqueline Bloemhof and Jo van Nunen

ERS-2005-030-LIS

http://hdl.handle.net/1765/6556

On Noncooperative Games and Minimax Theory

J.B.G. Frenk and G.Kassay

ERS-2005-036-LIS

http://hdl.handle.net/1765/6558

Optimal Storage Rack Design for a 3-dimensional Compact AS/RS

Tho Le-Duc and René B.M. de Koster

ERS-2005-041-LIS

http://hdl.handle.net/1765/6730

Strategies for Dealing with Drift During Implementation of ERP Systems

P.C. van Fenema and P.J. van Baalen

ERS-2005-043-LIS

http://hdl.handle.net/1765/6769

Modeling Industrial Lot Sizing Problems: A Review

Raf Jans and Zeger Degraeve

ERS-2005-049-LIS

http://hdl.handle.net/1765/6912

Cyclic Railway Timetabling: a Stochastic Optimization Approach

Leo G. Kroon, Rommert Dekker and Michiel J.C.M. Vromans

ERS-2005-051-LIS

http://hdl.handle.net/1765/6957

Linear Parametric Sensitivity Analysis of the Constraint Coefficient Matrix in Linear Programs

Rob A. Zuidwijk

ERS-2005-055-LIS

http://hdl.handle.net/1765/6991

Diffusion of Mobile Phones in China

Sunanda Sangwan and Louis-Francois Pau

ERS-2005-056-LIS

http://hdl.handle.net/1765/6989

An Elementary Proof of the Fritz-John and Karush-Kuhn-Tucker Conditions in Nonlinear Programming S.I. Birbil, J. B. G. Frenk and G. J. Still

ERS-2005-057-LIS

http://hdl.handle.net/1765/6992

General model for automated diagnosis of business performance

Emiel Caron and Hennie Daniels

ERS-2005-058-LIS

http://hdl.handle.net/1765/6987 
Exploring retailers' sensitivity to local sustainability policies

H.J. Quak and M.B.M. de Koster

ERS-2005-066-LIS

http://hdl.handle.net/1765/7057

Setting the holding cost rates in a multi-product system with remanufacturing

Umut Corbacıoğlu and Erwin A. van der Laan

ERS-2005-072-LIS

http://hdl.handle.net/1765/7095

A Dynamic Pricing Model for Coordinated Sales and Operations

Moritz Fleischmann, Joseph M. Hall and David F. Pyke

ERS-2005-074-LIS

http://hdl.handle.net/1765/7124

Optimal Redesign of the Dutch Road Network

M. Snelder, A.P.M. Wagelmans, J.M. Schrijver, H.J. van Zuylen and L.H. Immers

ERS-2005-091-LIS

* A complete overview of the ERIM Report Series Research in Management: https://ep.eur.nl/handle/1765/1

ERIM Research Programs:

LIS Business Processes, Logistics and Information Systems

ORG Organizing for Performance

MKT Marketing

F\&A Finance and Accounting

STR Strategy and Entrepreneurship 